\title{
Entrepreneurs and new ideas
}

\author{
Bruno Biais ${ }^{1}$ and Enrico Perotti ${ }^{2}$
}

June 2008

We thank the Editor, Jennifer Reinganum, and two anonymous referees, for helpful comments. Many thanks also to Amar Bhide, Sabrina Buti, Catherine Casamatta, Jacques Cremer, Guido Friebel, Denis Gromb, Michel Le Breton, Josh Lerner, Holger Muller, Patrick Rey, Jean Charles Rochet, Per Stromberg, Jean Tirole and participants at the Gerzensee Summer Symposium, the European Corporate Governance Network conference in Brussels, the CIFRA Workshop on Venture Capital in Amsterdam and seminars at the Universities of Amsterdam and Toulouse. The usual disclaimer applies.

\footnotetext{
${ }^{1}$ Toulouse University (CNRS/Gremaq, CRG-IAE and IDEI) and CEPR; biais@cict.fr.

${ }^{2}$ University of Amsterdam and CEPR; E.C.Perotti@uva.nl.
} 


\title{
Entrepreneurs and new ideas
}

\begin{abstract}
:
We study how early stage new ideas are turned into successful businesses. Even promising ideas can be unprofitable if they fail on one dimension, such as technical feasibility, correspondence to market demand, legality, or patentability. To screen good ideas the entrepreneur needs to hire experts who evaluate the idea along their dimensions of expertise. Sharing the idea, however, creates the risk that the expert would steal it. Yet, the idea-thief cannot contact any other expert, lest he should in turn steal the idea. Thus stealing leads to incomplete screening and is unattractive if the information of the other expert is critical and highly complementary. In such cases the entrepreneur can form a partnership with the experts, thus granting them the advantage of accessing each other's information. Yet, very valuable ideas cannot be shared because it is too tempting to steal them.
\end{abstract}

JEL Keywords: Innovation and invention, Entrepreneurship, Intelllectual Property Rights, Contracts, Incentives. 


\section{Entrepreneurs and new ideas}

\section{Introduction}

Successful business creation requires that unprofitable projects be weeded out. ${ }^{3}$ To screen an untried idea, each of its components must be assessed: its technical feasibility, the extent of the potential market or specific features of customer demand, its compliance with regulations, the ability to secure the necessary property rights, and the identification of contacts to access scarce logistic or managerial resources. These components are likely to be highly complementary, since the failure of the idea along even a single dimension may be sufficient to reveal that it is not viable. Thus entrepreneurs with novel concepts need to identify the critical dimensions along which the idea must be assessed, and then secure the collaboration of relevant experts for screening.

The need for collaboration, at the early stage of the entrepreneurial process, has been emphasized by the sociology of sciences. Innovation is a process which relies crucially on the interaction between several individuals (see Dodgson, 1993, Callon, 1989 and Latour, 1979). De Koning and Muzyka (2001) analyse the success factors in the approach of serially successful entrepreneurs and identify "the iterative process in discussing, investigating and evaluating ideas." They note that: "the building of business concepts could not be conducted in isolation." Bhide (2000) cites the reliance on experts as a success factor in a number of daring new enterprises. Aldrich (1999) reports that founding teams of 4 or 5 people are common in start-ups in knowledge intensive industries, and a $70 \%$ median percentage of start-up firms with two or more full-time partners. Mustar (1998) reports that almost all French high-tech start-ups initiated by scientists involve partners with complementary skills. Entrepreneurs usually associate former colleagues, scientific advisors, and people with industry experience. This takes

\footnotetext{
${ }^{3}$ For example, in the pharmaceutical industry, a survey estimated that only one out of 10,000 screened molecules turn out to be useful (The Economist, 2002). It concluded that: "Ideally, companies should be catching potential failures and terminating them in the early discovery phase."
} 
place at the early stage of the innovation process, well before financiers such as venture capitalists become involved.

Yet interaction with experts raises the risk that the better ideas, once communicated, may be stolen. ${ }^{4}$ Innovative ideas at an early stage of elaboration cannot be protected by patents, hence the idea-stealing problem is much more acute than in the case of more established and formalized ideas. A striking example is offered by the case of Robert Kearns. He offered his idea of the intermittent windshield sweeper to Ford, which declared no interest in the concept. Within months, Ford introduced wind--shield sweepers in its cars. ${ }^{5}$ Innovating entrepreneurs are extremely concerned with confidentiality issues (Anton, and Yao, 1994, 2002, 2003, 2004; Ueda, 2000; Rajan and Zingales, 2001). ${ }^{6}$ De Koning and Muzyka (2001) report a diffuse concern among entrepreneurs that "open discussions could lead to costly theft of ideas and opportunities." They report the case of an entrepreneur who "needs to discuss ideas with his partners and others ... Without $100 \%$ confidence that others will not steal his ideas he would not be able to discuss and therefore would not be as successful." Thus, entrepreneurs are faced with a dilemma similar to Arrow's (1962) paradox: On the one hand, potential buyers are not willing to pay before being told the idea and checking its value. On the other hand, they no longer need to pay for the idea once they have been told it.

Anton and Yao (1994) offer a solution to this paradox. They analyze how the seller of the idea can secure rents by credibly threatening to destroy the profits of thiefs by transmitting the idea to competitors. Cestone and White (1998) and Baccara and Razin (2002) also emphasize how the threat of competition can deter information leakage and idea stealing. Anton and Yao (2002 and 2004) enrich these analyses by considering partial disclosure of ideas and by analysing the choice

\footnotetext{
${ }^{4}$ Idea stealing is not an issue if the innovator is necessary to the development of the idea (Callon, 1989).

${ }^{5}$ See also the HBS "X-it" business case, concerning the appropriation by a producer of a novel design in fire escape which it had been offered to purchase.

${ }^{6}$ According to Bhide', over $70 \%$ of the founders of firms in the Inc 500 list of fast growing young firms replicated or modified ideas encountered in their previous employment. Besen and Raskind (1991) discuss how difficult it is to legally protect intellectual property rights.
} 
between patents and secrecy. An alternative solution is to control access to knowledge, as in Rajan and Zingales (2002) where the internal organization of the firm is designed to deter idea-stealing by employees. In Hellmann and Perotti (2004), firms restrict the circulation of ideas in order to capture their value. We complement this literature by showing that the entrepreneur can take advantage of the complementarity between the different dimensions of her innovative idea to mitigate the risk of idea-stealing.

To conduct this analysis, we develop the following simple model. The entrepreneur has an innovative idea, which is not yet patentable. The idea requires evaluation on two dimensions. The entrepreneur presents the idea to the experts, who privately observe signals on whether the project is viable, along their own line of expertise. The entrepreneur must extract this private information from the two experts, without letting them steal the idea. The entrepreneur offers to compensate the experts contingent on the profit of the venture, if it is implemented. To ensure that the appraisal is reliable, two conditions must hold. It is necessary that i) the experts do not falsely report a good signal when they have observed a bad one, and that ii) they prefer to join the venture rather than stealing the idea. The offer made by the entrepreneur to the experts can be interpreted as a partnership, to be implemented when the two experts report positive signals.

The key insight is that idea-stealing is constrained by its very nature. Suppose the first expert decides to steal the idea. Could he obtain information on the complementary dimension of the project? Since his expertise is known, by proposing to undertake the venture he reveals he observed a good signal. Having learned this, the second expert does not need him any longer. She can steal the idea to implement it herself. Hence, any expert tempted to steal the idea realizes he would need to undertake the project alone, without benefitting from further advice. This reduces the attractiveness of idea-stealing.

Thus, when the project is profitable only when two signals are good, the entrepreneur is able to form a partnership and avoid idea-stealing. In contrast, when an expert could profitably undertake the project alone after observing a good signal, idea-stealing is a real issue. This can lead to a market 
breakdown, in line with Arrow's (1962) paradox.

In addition, we also show that, if the entrepreneur can commit to an aggressive investment policy, pledging to undertake the project as soon as one expert accepts to join helps deterring idea-stealing. In this case, each expert knows that, if he steals the idea, he risks to compete with the entrepreneur when implementing the project. This reduces the attractiveness of idea-stealing, in line with previous analyses or the disciplining role of competition (see, Anton and Yao (1994), Cestone and White (1998) and Baccara and Razin (2002)). Note also that this rationalizes why such traits such as determination, obstinacy and overconfidence, would be associated with entrepreneurship. They help preventing idea appropriation.

Our paper complements the analyses of Aghion and Tirole (1994), Hellmann (2000) and Casamatta and Haretchabalet (2002), which do not consider the risk of idea stealing. Our approach is consistent with Lazear's (2002) findings (using a sample of Stanford MBAs with their education history) that entrepreneurs are typically nonspecialists with training or skills in different areas, and that an important aspect of their task is to combine talents. Similarly in our analysis, the entrepreneur is not an expert, but rather someone who knows enough about related aspects of the business to see some potential functional fit among existing resources, and needs specialists for advice and implementation.

Section 2 presents the model. Section 3 analyzes the conditions under which the entrepreneur can avoid idea stealing and describes the equilibria arising in our model. Section 4 discusses the robustness of the results. Section 5 outlines empirical implications of our theoretical analysis. We point out, e.g., that innovative enterprises should associate complementary experts as partners rather than consultants; that associating experts enhances the chances of success; and that the share of the initial entrepreneur should be relatively high in complex high technology ventures with high complementarities. Section 6 offers a brief conclusion. The proofs are in the appendix. 


\section{Model}

\section{Assumptions}

Ideas New ideas combine productive means in several dimensions. For simplicity we consider two dimensions only. The first dimension could correspond to a technological concept while the other could correspond to a business concept. An example is offered by Federal Express. Its founder, Frederick Smith, "had a bold vision for a company that would operate a national network of jets, trucks and personnel to provide reliable overnight delivery of letters and small packages" (Bhidé, 2000). Here we can think of the first dimension as the set of transportation techniques, and the second dimension as the demand for rapid post delivery.

Agents We define an entrepreneur as an agent endowed with a promising idea. Ideas are not always valuable. To be profitable, they must be feasible along each of the two dimensions. For example, before launching Federal Express, F. Smith had to find out if his idea was technically feasible, if planes and trucks could actually be used in combination to efficiently ship express mail, and also if there was sufficient demand for such a service.

The entrepreneur lacks the specialized knowledge to ascertain the feasibility of her idea and hence must obtain advice from specialized experts. In the case of Federal Express, Frederick Smith commissioned a study from A.T. Kearney: "Smith really wanted to know if the concept was practical" said the consultant who led the study (see Bhidé, 2000).

We assume that expertise is observable. Experts have an observable track record of academic and business achievements reflecting their skills. They are known for their participation in previous innovative ventures and the jobs they held previously reflect their technical skills. Furthermore, experts tend to know each other, at least by reputation.

At cost $L$, the entrepreneur can contact an expert and describe her idea. $L$ corresponds to the cost of contacting the expert, presenting the idea in a clear and structured way, and also the compensation 
of the expert for the time spent listening to the entrepreneur and evaluating the project. After being presented the project and after the cost $L$ has been incurred, each expert observes his private signal.

The entrepreneur contacts two experts, specialized in the two dimensions, $x$ and $y$ respectively. In line with the notion that the two signals correspond to different dimensions of the idea, we assume they are ex-ante independently distributed. Denote the signals: $\tilde{X}$ and $\tilde{Y}$. Each private signal can be good (in which case it takes the value 1) or bad (corresponding to $X$ or $Y=0$ ). Expert $x$ (resp. y) receives a good signal with probability $\pi_{x}$ (resp. $\pi_{y}$ ) or a bad signal with the complementary probability. Since we allow $\pi_{x}$ and $\pi_{y}$ to be different, the signals have different significance.

Cash flows The entrepreneur obtains the idea and contacts the experts at time 1 . If the project is undertaken, it can generate cash flows at time 2. For simplicity we normalize the discount rate to 1. If both experts observe good signals, the idea is excellent. In that case, if only one firm implements the project, at time 2 it generates revenues equal to $H$ with probability $\mu$ or $h$ with the complementary probability, with $H>h .^{7}$ If the project is operated by more than one firm, each stands to generate lower revenues because of competition. To take this into account in the simplest possible way, we assume that, under competition, revenues are scaled down by a factor $\delta \in[0,1]$. If one of the signals is good and the other is bad, then the cash flow at time 2 is $h$, if the project is implemented by only one firm, while competition scales the revenues of each firm down to $\delta h$. Finally, if both signals are bad, the project yields zero cash flow.

Denote $H(.,$.$) the function mapping the two signals into the expected time 2$ cash flows, when the project is implemented by a single firm: $H(1,1)=\mu H+(1-\mu) h, H(1,0)=H(0,1)=h$, and $H(0,0)=0$. Since by assumption the two signals play a symmetric role in the expected cash flow, slightly abusing notations, we can rewrite the function simply as a function of the number of signals that are good $(n): H(n), n \in\{0,1,2\}$.

\footnotetext{
${ }^{7}$ The residual uncertainty with two good signals is not necessary, but raises the possibility to distinguish different types of financial claims, such as debt or equity for example.
} 
Associated to each dimension of expertise is a resource (reflecting specialized human, physical or financial capital) which needs to be contributed at time 1 for the implementation of the idea. We assume that such resources can be contributed by the experts at cost $c$, if they agree to participate. For simplicity, we describe this resource contribution as observable and contractible, ruling out any moral hazard. Thus we focus only on the adverse selection problem in aggregating privately observed expert signals. We consider the case where the development cost $(2 c)$ is paid by the experts. In a previous draft of the paper we showed that our results were robust to an arbitrary division of this cost between the entrepreneur and the experts.

Complementarity Although the signals play symmetrical roles, they are not substitutes; rather they correspond to the two different dimensions along which the project must be evaluated, and thus can be complementary. ${ }^{8}$ Complementarity arises if the cash flow function $H(n)$ is convex. Convexity means that the marginal increase in value implied by a positive signal is greater if the other signal is also positive, or, more formally:

$$
H(2)-H(1)=(\mu H+(1-\mu) h)-h \geq H(1)-H(0)=h,
$$

that is: $H \geq \frac{1+\mu}{\mu} h$.We assume this inequality holds, to focus on the complementary case, which we believe to be the most realistic for innovative projects. The argument is that in an innovative project, both components of the idea must have a good functional fit, so that if one fits but the second does not, the concept is worth much less.

An extreme form of complementarity is when the project generates positive cash flows only if both signals are good (i.e., $h=0$ ). For example, a start-up would generate a positive cash flow only if its product is technically feasible and there is a sufficient market for it. In that case the signals enter in the value function in a multiplicative form, i.e.: $H(X, Y)=X Y \mu H$, which corresponds to the case of maximum convexity of the cash flow function $H(n)$. Arguably, this case probably describes

\footnotetext{
${ }^{8}$ This differs from the typical assumption in the analysis of financial prices under heterogeneous information, where signals are equal to the sum of a common underlying value and individual noise.
} 
particularly complex ideas, in which each dimension of the idea "must fit exactly". At the opposite extreme is the case where the cash flow function $H(n)$ is linear in the number of good signals, which arises if $H=\frac{1+\mu}{\mu} h$. In this additive case, a second positive signals adds just as much as the first. The cash flow as a function of $n$ is graphically represented in Figure 1. (Note that the sequence of signals does not matter).

To assess the effect of changes in the degree of complementarity, it is convenient to consider a change in $h$ compensated by a change in $H$, such that the expected cash-flow from the project when the two signals are positive remains constant. Denote $\epsilon$ this change in $h$ (i.e., $h$ goes to $h-\epsilon$ ). The corresponding change in $H$ is $\frac{1-\mu}{\mu} \epsilon$ (i.e., $H$ goes $H+\frac{1-\mu}{\mu} \epsilon$ ). The greater $\epsilon$, the more convex the resulting function, the more complementary the signals.

Net Present Value If the project is undertaken by a single firm, without any advice from the experts, its expected net present value is:

$$
E(H(\tilde{X}, \tilde{Y}))-2 c=\left[\pi_{x} \pi_{y}(\mu H+(1-\mu) h)+\left(\pi_{x}\left(1-\pi_{y}\right)+\pi_{y}\left(1-\pi_{x}\right)\right) h\right]-2 c .
$$

We assume that this ex-ante net value is negative. On the other hand, if the entreprenur consults the experts and both signals are good, the expected net present value of the project implemented by a single firm is positive:

$$
E(H(\tilde{X}, \tilde{Y}) \mid X=1, Y=1)-2(c+L)=\mu H+(1-\mu) h-2(c+L)>0 .
$$

Note that, in contrast with the case where no expert was consulted (corresponding to equation (1)), the cost of expert consultation is included in condition (2). We assume that, after observing that one of the two signals is positive and the other negative, the net value of the project is negative, i.e.: $h<2 c$. This assumption is in line with our focus on the complementary case, and obviously holds in the multiplicative case (where $h=0$ ). To allow for positive net value conditional on two signals in the additive case (i.e. when the function $H(n)$ is linear), we also assume that $h>c+L$. 
Designing the partnership The creative role of entrepreneurs in our model has two aspects: First, entrepreneurs have innovative ideas. Second, entrepreneurs initiate the process of venture formation: they contact experts, elicit their information and form a partnership. To model this second aspect, we take a principal agent approach. The entrepreneur, who initiates the venture, is the principal, and designs the contract. The experts, who observe private signals, are the agents. The contract must be designed so that their incentive compatibility and participation constraints hold. ${ }^{9}$

The entrepreneur presents her idea and offers the contract to the experts, separately and simultaneously. The contract describes the project, the compensation of the experts contingent on joining and their resource commitments. The entrepreneur signs this contract before offering it to the experts, thus she can commit to the offer. The experts answer with announcements about their private signals. The challenge for the entrepreneur is to elicit truthful revelation of these signals and to prevent the experts from stealing the idea. ${ }^{10}$ The contract involves a decision rule mapping the announcements of the experts into the decision to undertake in the project or not. If the project is undertaken, the experts must commit their resources, at cost $c$. The mechanism also specifies the compensation of the experts, when the project is undertaken. This is a transfer function contingent on the final realization of the cash flow and the announced signals. The total transfer is between 0 and the realized cash flow. For simplicity, this cash flow is assumed to be observable and contractible.

Once the two signals have been observed, the project has positive net present value only if both signals are positive. Hence, under truthful reporting, the only renegociation proof policy is to implement the project if and only if the two reports are positive and the entrepreneur obtains non negative expected returns. In our main analysis, we focus on this renegociation-proof policy. In Section 4, we investigate the optimal mechanism arising when the entrepreneur can commit ex-ante to policies

\footnotetext{
${ }^{9}$ Strictly speaking, our principal is privately informed. But in the consultation phase the experts observe the idea. From that point on, we are in the standard uninformed principal case. This contrasts with Anton and Yao (2002) where the entrepreneur needs to signal her type.

${ }^{10}$ At this preliminary stage of the innovation process, the idea is still too general and ahead of actual implementation to be patentable. Only after being actually implemented is the idea concrete enough to be protected by a patent.
} 
which are not renegociation proof ex-post. There, we show how the entrepreneur can rely on this commitment power to implement more aggressive investment strategies, useful to deter idea-stealing.

When the decision rule is to undertake the project if and only if the two reports are good the contract can be summarized by two transfers function contingent on the final cash flow: $\varphi_{x}($.$) and$ $\varphi_{y}($.$) . The mechanism design problem for the entrepreneur is to choose \varphi_{x}($.$) and \varphi_{y}($.$) to maximize$ her expected gains:

$$
\pi_{y} \pi_{x}\left[\mu\left(H-\varphi_{x}(H)-\varphi_{y}(H)\right)+(1-\mu)\left(h-\varphi_{x}(h)-\varphi_{y}(h)\right)\right]-2 L,
$$

subject to the participation constraints of the experts, requiring that their expected compensation be at least as large as the development cost they incur:

$$
\mu \varphi_{i}(H)+(1-\mu) \varphi_{i}(h) \geq c \quad \text { for } i \in\{x, y\}
$$

and the condition that the experts truthfully report their type.

In line with our principal agent approach, the entrepreneur makes a take it or leave it offer to the experts when he offers them the contract. If condition (3) holds as an equality for expert $i$, then this expert just breaks even. But, as shown below, for certain parameter values incentive compatibility implies that informational rents must be left to the experts. In that case, the entrepreneur does not have all the bargaining power, in the sense that he does not capture the entire net present value of the project. Thus, by computing the informational rents of the experts, we characterize their endogenous bargaining power.

To conclude the presentation of our model, and clarify the timing of the moves, we briefly summarize the extensive form of the game. At the beginning of time 1, the entrepreneur obtains the idea. Then, she can contact the experts, and present them her idea and the contract at cost $2 L$. After being told the idea, the experts privately observe their signals and separately and simultaneously report their type to the entrepreneur. If both experts report a good signal, they join the partnership, and contribute the resource necessary to the development of the project (at cost $c$ ). Instead of joining the partnership, each expert can steal the idea. In that case, he can then implement the idea alone, or 
contact another expert, in order to obtain information relevant along the complementary dimension of the idea. At time 2, if the project has been undertaken, cash flows are obtained. If the partnership has been formed, the transfers conditional on these cash flows are distributed.

\section{New ideas in equilibrium}

In this section we study when the formation of the partnership and the implementation of the new idea are feasible.

Preventing gambling The entrepreneur must prevent the expert with a bad signal from reporting a good signal. Since even after a bad signal there is a chance that the project will produce cash-flow $h$, the expert might claim a positive signal to "gamble" on a positive signal by the other expert. Since when he truthfully reports a bad signal he gets 0 , the expert has no incentive to falsely pretend he had a good signal if:

$$
\pi_{i}\left(\varphi_{j}(h)-c\right) \leq 0,(i, j) \in\{(x, y),(y, x)\}
$$

This condition implies that the entrepreneur must promise only limited cash flow to the experts in the bad state $h$, i.e., cash flow lower than the cost of the resource $c$. Hence, the structure of the claim held by the experts has to be payoff-contingent to ensure reliability. Furthermore, since the expert has to receive less than $c$ in the low state to avoid gambling, he must be receiving more than $c$ in the high state to break even. Thus we can state our first proposition:

Proposition 1: The compensation of the expert is increasing in the cash-flows generated by the project.

This is consistent with the entrepreneur offering the experts to join a partnership, as discussed further at the end of this section. 
Preventing idea stealing Suppose that expert $x$ has a positive evaluation of the project. Instead of reporting this positive signal and joining the partnership, he could decide to report a bad signal to deter the entrepreneur from engaging in the venture. Then the expert would undertake the project without the entrepreneur. This would amount to stealing the entrepreneur's idea. ${ }^{11}$

The risk of idea stealing could be mitigated if the experts could sign a no-compete clause before hearing the idea. Signing such a clause related to the specific idea without learning the idea itself is logically impossible. This leaves open the issue whether the experts could sign a broader clause, committing them not to start any project in the general line of business. In the first part of the paper (Section 3), we simply assume this is not possible. While this assumption is in line with the difficulty to enforce no compete clauses in practice (see, e.g., Besen and Raskind, 1991), in Section 4 we also analyze the case where no compete clauses can be enforced. In that section, we assume that, while some of the potential entrepreneurs really have observed promising ideas, others in fact have observed worthless ideas. Until they have inspected the idea, the experts cannot tell if the entrepreneur is really serious. Thus they do not want to restrict their future options and be at risk of being blackmailed (see Anton and Yao, 2003). This limits their willingness to sign broad no-compete clauses ex-ante.

Should the expert decide to steal the idea, he could use it in two different ways. First, he could set up the firm and exploit the idea without involving another expert for further appraisal. In this case he would supply his own effort (at $\operatorname{cost} c$ ), and he could acquire the complementary resource at the market price $c .^{12}$ The corresponding expected profit of the expert would be: ${ }^{13}$

$$
E(H(\tilde{X}, \tilde{Y}) \mid X=1)-2 c=\pi_{y}(\mu H+(1-\mu) h)+\left(1-\pi_{y}\right) h-2 c .
$$

\footnotetext{
${ }^{11}$ The idea can be stolen because it is too preliminary to be patented. This is in line with the evidence, surveyed in Besen and Raskind (1991), that it is difficult to protect intellectual property rights. See also Anton and Yao (2003).

${ }^{12}$ Our assumption that this effort can be purchased is in line with our assumption that it is observable and contractible.

${ }^{13}$ If the expert steals the idea and implements it, the entrepreneur cannot observe this until the end of the period and the cash flow realization. At this point, since he has concretely implemented the idea, the expert can patent it. Hence, the entrepreneur cannot retaliate by implementing the idea herself.
} 
Alternatively, the expert ( say $x$ ) could go to an expert competent relative to the other dimension, describe her the idea and offer her to set up a partnership together. ${ }^{14}$ The latter can either accept the offer or reject it. But at this stage, the second expert can also decide to undertake the project herself, if she feels it profitable. Thus expert $x$ also faces the risk of idea stealing. As stated in the next proposition, this risk prevents the expert from successfully stealing the idea and implementing it in collaboration with another expert.

Proposition 2: There is no equilibrium where expert $x$, after hearing the idea from the entrepreneur, would be able to contact another expert and undertake the project with her.

The intuition of this result is the following. Suppose expert $x$ steals the idea, contacts an expert competent in the other dimension, tells her the idea and offers her to form a partnership. If this reveals $x$ 's signal (as would be the case if $x$ stole the idea only after observing a good signal), then once she has been contacted by $x$, the second expert does not need $x$ any longer. Hence if the idea is profitable, she is better off implementing it alone rather than sharing its profit with $x$. Consider the alternative case where $x$ 's offer does not reveal his own signal, i.e., a candidate pooling equilibrium. Then the second expert is willing to accept $x$ 's offer only if, conditional on her own signal alone, the project is expected to be profitable. However, in this case, she prefers to implement the idea alone rather than to share its profits with $x$. Proposition 2 directly implies the following:

Proposition 3: Should one of the experts decide to conceal from the entrepreneur that he had a good signal, the best he could do would be to undertake the project alone.

This is our first important result. After stealing the idea, the expert himself faces the risk of idea stealing. Thus an expert who steals the idea can only undertake the project alone. This limits the profitability of idea stealing, and increases the ability of an entrepreneur to reliably aggregate the signals of the experts.

\footnotetext{
${ }^{14}$ This could be the expert initially contacted by the entrepreneur or another one.
} 
These results rely on the assumption that expertise is observable. If it was not, an expert in dimension $x$ could contact another expert, in dimension $y$, pretending to be technically incompetent. While logically possible, we believe this is implausible. When approached and presented with a venture proposition, expert $y$ will naturally collect information about his potential business partner and be able to find out if the latter is really ignorant.

Relying on Propositions 2 and 3, we can state the next proposition:

Proposition 4: The condition under which, after observing a good signal, expert $i$ does not steal the idea is:

$$
\pi_{j}\left[\mu \varphi_{i}(H)+(1-\mu) \varphi_{i}(h)-c\right] \geq \pi_{j}[\mu H+(1-\mu) h]+\left(1-\pi_{j}\right) h-2 c,(i, j) \in\{(x, y),(y, x)\} .
$$

The left-hand side of inequality (4) is the expected profit of the expert if he truthfully reports a good signal and joins the project. The right-hand side of the inequality is his expected profit if he undertakes the project alone. This expected profit determines the level of the informational rent which the entrepreneur must leave to the expert to prevent idea-stealing. If it is non positive, then the experts do not obtain rents.

The determinants of the informational rents of the experts We consider next the comparative statics of the economic variables determining the rents of the experts. The greater the development cost, the less demanding the condition (4) under which neither the experts don't steal the idea. We can then state the following:

Proposition 5: The greater the development cost c, the more attractive it is for the experts to join the partnership rather than undertaking the project alone, and the lower their informational rents.

For each expert, the advantage of joining the partnership is that it enables him to incur the development cost only when the signal of the other expert is also good. This is especially attractive when the development cost is large.

The condition under which expert $x$ does not steal the idea can be rewritten as: 


$$
\frac{2 c-\left(1-\pi_{y}\right) h}{\pi_{y}} \geq \mu\left(H-\varphi_{x}(H)\right)+(1-\mu)\left(h-\varphi_{y}(h)\right)+c .
$$

The left-hand side is decreasing in $\pi_{y}$. Hence the condition is more demanding if the probability that the other expert observes a good signal is large. The lower this probability, the more likely it is that ex ante the project has negative net value, and thus the more crucial it is to rely on the expertise of $y$ to avoid engaging in a loss-making project. Thus, we can state the following result:

Proposition 6: The less likely it is that the signal of expert $y$ is positive, the less attractive it is for expert $x$ to undertake the project alone, and the lower the rent that expert $x$ can obtain.

Low values of $\pi_{x}$ and $\pi_{y}$ corresponds to more "daring" ideas, which are ex-ante less likely to be viable and for which a complete appraisal is more critical. In this case, the entrepreneur manages to capture a greater fraction of value because she is essential in aggregating the critical signals. Correspondingly, there is a threshold level for each expert beyond which the other expert cannot undertake the project alone. Ats this point, it is convenient to define $\beta$ as follows:

$$
\beta=\frac{2 c-h}{\mu(H-h)}
$$

Relying on this notation, we state our next proposition:

Proposition 7: If the probability of a positive signal by expert $y$ is sufficiently low, in the sense that $\pi_{y}<\beta$, then it never pays for agent $x$ to steal the idea and implement the project alone.

On the other hand, if $\pi_{y}>\beta$, then the right-hand-side of inequality (4) is strictly positive. So the expert must be promised a rent to prevent idea-stealing. Hence we can state the following proposition:

Proposition 8: Expert $x$ earns a rent, if and only if $\pi_{y}>\beta$.

When is the partnership viable? We now examine under what conditions the partnership is viable and the entrepreneur can aggregate the experts' signals. We established that the entrepreneur must concede expert $x$ an informational rent to avoid idea-stealing when $\pi_{y}$ is relatively large. We will 
see that when $\pi_{y}$ and $\pi_{x}$ are large, the partnership is not viable. Without loss of generality consider the case where: $\pi_{x} \geq \pi_{y}$. In the following we spell out the three types of equilibria which can arise when one expert, both or none are critical.

We consider first the case where the ex-ante expected value of the project is low and none of the two experts could profitably undertake it alone. In this case the entrepreneur does not need to leave rents to the experts. Information aggregation by the entrepreneur is facilitated, since both experts need each other, and only the entrepreneur can arrange for them to commit to a partnership.

Proposition 9: If $\beta>\pi_{x} \geq \pi_{y}$, experts earn no rents. In this case the entrepreneur contacts the experts, the partnership is formed and the project is implemented when both experts observe good signals. The entrepreneur captures the entire ex-ante expected net present value of the project: $\pi_{x} \pi_{y}[\mu H+(1-\mu) h-2(c+L)]$.

Next we consider the case when only one expert could profitably undertake the project alone.

Proposition 10: If $\pi_{x}>\beta>\pi_{y}$, expert $y$ must be left an information rent to discourage ideastealing; in contrast, expert $x$ obtains no rent. In this case, the partnership is viable. Furthermore, the ex-ante expected profit of the entrepreneur equals: $\left(1-\pi_{x}\right) \pi_{y}[2 c-h]>0$.

In that case, the expected profit of the entrepreneur is independent of $H$. Indeed, an increase in $H$ has two countervailing effects. On the one hand it increases the expected cash-flow from the project; on the other hand it increases the rent which must be left to expert $y$. The proposition shows that the two effects exactly offset each other. The result also implies that, when only one of the experts earn rents, the residual expected profit left to the entrepreneur is sufficiently large to undertake the project.

Next we consider the case where each of the two experts could undertake the project alone. This case turns out to be the most challenging for the aggregation of signals.

Proposition 11: When $\pi_{x}>\pi_{y}>\beta$, then, if $\pi_{y}>\frac{\pi_{x}}{\pi_{x}\left(1+\frac{1}{\beta}\right)-1}$, the rents which must be left to the experts are so large that it is no longer profitable for the entrepreneur to hire the experts to evaluate 
her idea. Otherwise, the entrepreneur will hire the two experts, and her ex-ante expected profit is:

$$
2 c\left(\pi_{y}+\pi_{x}-\pi_{y} \pi_{x}\right)-\left[\left(1-\pi_{y}\right) \pi_{x}+\left(1-\pi_{x}\right) \pi_{y}\right] h-\pi_{x} \pi_{y}(\mu H+(1-\mu) h) .
$$

When $\pi_{x}$ and $\pi_{y}$ are large, idea stealing is too attractive and the entrepreneur cannot retain any share of the surplus after contacting the experts. Thus there is a market breakdown: the innovative idea is not implemented, even when its net present value is positive. This is in the line of Arrow's (1962) paradox. Also in that case, even if the entrepreneur can profitably implement the project, his profit is decreasing in $H$. An increase in $H$ makes the project more valuable, but it also raises the informational rent of the experts. When $\pi_{y}>\beta$ informational rents are large, and the latter effect is stronger than the former.

The different equilibrium outcomes arising for different values of the parameters are represented in Figure 2. The figure illustrates that, when $\pi_{x}$ and $\pi_{y}$ are low, the project can be undertaken and the entrepreneur can profitably exploit her innovative idea. In contrast, when $\pi_{x}$ and $\pi_{y}$ are high, there is a market breakdown.

The key parameter of the equilibrium regions in Figure 2 is $\beta$. The smaller $\beta$, the lower the no-rent region, and the greater the market breakdown region. Note that $\beta$ is decreasing in the possible cash flows from the project: $H$ and $h$. This is in line with our above remark that large cash-flows make idea stealing more attractive and thus exacerbate the problem faced by the entrepreneur.

Relying on the three propositions above, the following proposition (illustrated in Figure 3) characterizes the evolution of the profit of the entrepreneur as $H$ varies: $^{15}$

Proposition 12: The expected profit of the entrepreneur is not monotonic in the high realization of the cash flow, $H$.

Similarly, it is straightforward to show that the expected profit of the entrepreneur is not monotonic in the a priori probabilities that the signals of the experts will be good: On the one hand, when these

\footnotetext{
${ }^{15}$ The upper and lower bounds on $\mathrm{H}$ in the figure reflect our assumptions that the project has negative net present value before screening, and positive net present value conditionally on two good signals, respectively.
} 
probabilities are low, both experts need each other, and the entrepreneur captures the entire value of the project. In that region, the expected profit of the entrepreneur is increasing in $\pi_{x}$ and $\pi_{y}$. On the other hand, when these probabilities are large, the experts could undertake the project alone, and hence must be left a rent. When $\pi_{x}$ and $\pi_{y}$ are too large, we are in the market breakdown region and the expected profit of the entrepreneur is zero.

Putting together the counter-intuitive results we obtained relative to i) the ex-ante probability of success $\left(\pi_{x} \pi_{y}\right)$ and ii) the level of payoffs, our model shows that the best ideas cannot be implemented - because it is too tempting to steal them.

How does complementarity affect the ability of the entrepreneur to profitably undertake the project? Recall that complementarity is related to the convexity of the payoff function $H(.,$.$) . Con-$ sider an increase in its degree of convexity, corresponding to a decrease of $h$ to $h-\epsilon$, compensated by an increase of $H$ to $H+\frac{1-\mu}{\mu} \epsilon$. In this case, $\beta$ changes from $\frac{2 c-h}{\mu(H-h)}$ to $\frac{2 c-h+\epsilon}{\mu(H-h)+\epsilon}$. It is easy to see that this is increasing in $\epsilon$. Hence, we can state the next proposition:

Proposition 13: The more complementary the signals the smaller the region in the parameter space for which there is a market breakdown.

The more complementarity the signals are, the more attractive it is for each expert to join the partnership to benefit from the value added by the signal of the other expert. This helps the entrepreneur preventing idea-stealing.

What happens when the informational rents are so large that the entrepreneur cannot profitably hire the two experts? In that case, since we assume that the ex-ante expected cash flow from the project is below $2 c$, it would not be optimal for the entrepreneur to undertake the project alone, without the advice of the experts.

Could the entrepreneur choose to go to only one expert, say $x$ ? Obviously this can lead to undertaking the project only if it has positive net expected value when the expert has observed a positive signal, that is: $\pi_{y}[\mu H+(1-\mu) h]+\left(1-\pi_{y}\right) h>2 c+L$. In that case, consider the reaction of 
the expert after being presented the idea. If he observes a bad signal, then he has no incentive to lie. But if he observes a good signal and joins the partnership, his expected gain is:

$$
\alpha_{x}\left(\pi_{y}[\mu H+(1-\mu) h]+\left(1-\pi_{y}\right) h\right)-c
$$

while if he steals the idea and implement it alone, his expected profit is:

$$
\pi_{y}[\mu H+(1-\mu) h]+\left(1-\pi_{y}\right) h-2 c .
$$

The former is greater than the latter if and only if:

$$
\alpha_{x}>1-\frac{c}{\pi_{y}[\mu H+(1-\mu) h]+\left(1-\pi_{y}\right) h} .
$$

The participation constraint of the entrepreneur is:

$$
\left(1-\alpha_{x}\right)\left(\pi_{y}[\mu H+(1-\mu) h]+\left(1-\pi_{y}\right) h\right)-(c+L)>0
$$

Comparing the two conditions shows that satisfying the incentive compatibility condition prevents from leaving the entrepreneur strictly positive profits. Thus, going to one expert only is not an attractive course of action for the entrepreneur.

The interpretation is simple. It is advantageous for an expert to join the partnership only if by doing so he can benefit from the advice of the other expert, and thus avoid to incur the development cost when the idea is bad. This benefit cannot be obtained when the entrepreneur goes to see only one expert.

Compensating the experts with financial claims Proposition 1 states that the compensation of the experts must be increasing in the cash-flows from the project. We now characterize this compensation more precisely. For simplicity focus on the case where the two experts have identically critical signals $\left(\pi_{x}=\pi_{y}=\pi\right)$. In that case, we obtain the following proposition: 
Proposition 14: The optimal direct mechanism can be implemented by offering the experts equity or convertible debt.

Implementing the optimal mechanism with equity is consistent with interpreting it as a partnership. That the mechanism can be implemented equivalently with equity or convertible debt underscores that, in our simple model, the precise allocation of cash flows across states does not play a central role. All that is required is that the claims' payoff in the low state be sufficiently low to deter gambling, and the total expected payoff be large enough to avoid idea stealing and enable the experts to break even. Enriching the model could lead to sharper implications for financial contracts. For example, if the implementation cost was (at least partly) unobservable, this would raise moral hazard issues. Cash-flow sensitive claims, such as equity or options, would cope with these problems more effectively that insensitive claims such as debt.

\section{Robustness and discussion}

Non binary signals The key argument in our analysis is that, when contacting another expert, the idea-thief reveals his own signal was positive. One might wonder whether this stems from our assumption that signals take only two values: bad or good. With a more complex, non-binary, signal structure, could the expert-thief profitably contact another expert?

To study this point, we slightly relax our binary signal assumption. For simplicity, we let $\pi_{x}=$ $\pi_{y}=\pi$ and $\mu=1$, and for expert $y$ we keep the same signal structure as above. But, for expert $x$, instead of two values, the signal can take three values: good, neutral or bad. To generate such a signal structure in a simple way, we make the following assumption. With probability $\lambda$ the expert receives a precise signal. In that case, with probability $\pi$ the project is good in the dimension of expertise of $x$, and accordingly the signal is good. With probability $1-\pi$, the project is bad, and so is the signal. Furthermore, with probability $1-\lambda$, the agent receives an imprecise, neutral signal. In that case, while the expert remains uninformed, the project is actually good in his dimension with probability $\pi$ 
and bad with probability $1-\pi$. Thus, the ex-ante probabillity that the project is viable in dimension $x$ is still $\pi$.

Conditionally on two good signals, the expected value of the project is $H-2 c$. Conditionally on one good signal and one neutral signal it is $(\pi H+(1-\pi) h)-2 c$. Conditionally on a good signal and a bad one, the expected value of the project is: $h-2 c<0$. Conditionally on two neutral signals it is: $\pi^{2} H-2 c<0$.

First consider the case where, conditionally on one neutral signal, the project cannot be profitable, even if the other signal is good, i.e., $(\pi H+(1-\pi) h)-2 c<0$. In that case, after observing a neutral signal, the first expert is not tempted to steal the idea and contact another expert. Therefore, contacting another expert reveals that the idea-thief has observed a good signal, just like in our analysis above.

Now turn to the case where $(\pi H+(1-\pi) h)-2 c>0$, i.e., conditionally on a neutral signal, the project would be profitable if the other signal turns out to be good. In that case, expert $x$ could be tempted to steal the idea after observing a good signal or a neutral one. Since, both of these types would contact $y$, expert $x$ would not fully reveal his own signal when approaching the other expert. He would only reveal that he had observed a neutral or a good signal.

Of course, if $y$ has observed a bad signal, he knows the project is unprofitable and idea stealing is not an issue. But what if expert $y$ has observed a good signal? If he accepts the offer of $x$, his expected profit is:

$$
\frac{\pi}{\lambda \pi+(1-\lambda)} \alpha H-c
$$

If he lies to $x$, announces that his signal was bad, and undertakes the project alone his expected profit is:

$$
\frac{\pi}{\lambda \pi+(1-\lambda)} H-2 c
$$

Thus, a necessary condition for $y$ not to steal the idea from $x$ is:

$$
1-\alpha<\frac{c}{H}\left(\lambda+\frac{1-\lambda}{\pi}\right)
$$


On the other hand, a necessary condition for $x$ to break even after observing a neutral signal is: $\pi(1-\alpha) H-c>0$, that is:

$$
1-\alpha>\frac{c}{H} \frac{1}{\pi}
$$

These two conditions are consistent only if:

$$
\frac{c}{H}\left(\lambda+\frac{1-\lambda}{\pi}\right)>\frac{c}{H} \frac{1}{\pi}
$$

which implies $\pi>1$, a contradiction.

Hence, like in the case of binary signals, the idea-stealing expert cannot hope to benefit from the expertise of the other expert to screen unprofitable ideas: When $x$ contacts $y$, the latter infers that the former has observed either a positive or a neutral signal. Once he has extracted that information, $y$ cannot obtain any additional benefit from collaborating with $x$. Hence he prefers to undertake the project alone rather than sharing the rent with $x$. Anticipating this behavior, $x$ realizes that, if he steals the idea, he will not be able to benefit from any expertise in dimension $y$.

Would the experts sign a no-compete agreement before seeing the idea ? Could the entrepreneur ask the experts to sign a broad no-compete agreement before showing them the idea? This would prevent them from stealing the idea. As discussed above, such no-compete clauses are difficult to enforce (see Besen and Raskind, 1991, for example). We now show that, even if they were perfectly enforceable, they could be ineffective to solve the idea stealing problem, when the quality of the entrepreneur's idea is a priori uncertain.

Extending the model analyzed above, consider the case where with probability $\nu$ the idea of the entrepreneur is promising, while with the complementary probability it is worthless. The potential entrepreneur does not know if her idea is promising, but the experts, after being told the idea, immediately find out if the idea is valueless. This is in line with the discrimination process followed by venture capitalists (see e.g. Fenn, Liang and Prowse, 1995). Approximately $90 \%$ of the enterprise projects they receive are immediately rejected. The remaining $10 \%$ are then inspected carefully (which corresponds in our model to the evaluation of the project by the experts). 
Suppose the entrepreneur contacts experts $x$ and $y$, and asks them to sign a broad no-compete clause before being presented the idea. Denote $K$ the opportunity cost for the experts of the nocompete clause. This is the opportunity cost of passing up all the other interesting projects they might encounter later in this line of business. For simplicity, consider the case where $\pi=\pi_{x}, \pi_{y}$. Since the no-compete clause prevents idea stealing, the entrepreneur can actually sell her idea to the two experts, at price $P \geq 0$, and allocate to each of them half of the its cash flows if:

$$
\nu \pi^{2}\left[\frac{\mu H+(1-\mu) h}{2}-c\right]>P+K
$$

The left-hand-side is the expected net present value of the cash-flows to be received by the expert, while the right-hand-side is the cost borne by the expert. There is no positive price at which this transaction can take place if:

$$
\nu<\frac{K}{\pi^{2}\left[\frac{\mu H+(1-\mu) h}{2}-c\right]} .
$$

Thus the experts will not agree to sign a no-compete clause before seeing the idea if the a priori probability that the entrepreneur's idea is promising is small relative to the ratio of the opportunity cost of this clause for the experts to the net present value of promising ideas.

\section{What if the entrepreneur can commit to policies which are optimal ex-ante but not} renegociation-proof ex-post? So far we have focused on the renegotiation-proof policy according to which the contract is implemented if and only if both experts report good signals. We now extend our analysis to the case where the entrepreneur enjoys more commitment power. She can commit to implement the project as soon as at least one of the two reports is positive. This would be consistent with the view that entrepreneurs are obstinate and insist on undertaking their projects even when they face reluctance and weak support. Such an attitude could be portrayed as irrational. Yet, in our model, it can actually be ex-ante beneficial and enable the entrepreneur to efficiently deter idea-stealing. For simplicity, we develop the analysis in the symmetric case where $\pi_{x}=\pi_{y}=\pi$. 
As shown in the previous section, when $\pi<\beta$, experts are critical and the entrepreneur can reap all the rents from the experts. In that case, it is optimal to commit to the first best investment policy and implement the project only if both signals are good. Now turn to the case where $\pi>\beta$, so that each of the experts could undertake the project alone as a monopolist. If the entrepreneur sticks to the first best investment policy, her expected profit is positive if:

$$
\pi<\frac{2 \beta}{1+\beta} \text {. }
$$

Hereafter, we study whether, when that condition does not hold, the entrepreneur can earn positive expected profits by following a more aggressive investment policy. Consider the strategy of investing as soon as one of the two experts reports a good signal. By construction, since the experts are not critical, this yields positive social surplus ex-ante. This translates into positive ex-ante expected profits for the entrepreneur if this surplus is greater than the rents which must be left to the experts to deter idea-stealing.

Under this more aggressive investment policy, if one expert stole the idea and implemented it by himself, his expected profit would be:

$$
\pi(\delta H(2)-2 c)+(1-\pi)(h-2 c) .
$$

$\delta H(2)$ corresponds to the revenue earned by the expert when both he and the expert implement the idea simultaneously. $\delta<1$ is a scaling factor reflecting the decline in the revenue of each firm due to competition. This decline in revenue reduces the attractiveness of idea stealing for the expert. Manipulating equation (10) shows that the expected profit of the stealing expert is negative if:

$$
\delta<\frac{2 c-(1-\pi) h}{\pi H(2)} \equiv \delta^{*} \in[0,1] .
$$

When $\delta<\delta^{*}$, under the aggressive investment policy experts earn no rent. Thus, by committing to implementing the project as soon as one signal is good, the entrepreneur is able to capture the entire social surplus and earn positive expected profits. This contrasts with the case where the entrepreneur cannot commit to non renegociation-proof policies, whereby she could not reap any benefits from her 
idea. When competition significantly reduces the profits of the firm, by commiting to enter as soon as one signal is good, the entrepreneur "occupies the grounds" and deters entry by the experts.

What happens when $\delta>\delta^{*}$ ? In that case, the expected profit of the entrepreneur, equal to the social surplus generated by the project minus the experts' rents is:

$$
\left[\pi^{2}(H(2)-2 c)+2 \pi(1-\pi)(h-2 c)\right]-2 \pi[\pi(\delta H(2)-c)+(1-\pi)(h-c)]
$$

This is positive if:

$$
\delta<\frac{1}{2}-\left(\frac{1-\pi}{\pi}\right) \frac{c}{H(2)} \equiv \delta^{* *}
$$

Thus, if $\delta^{*}<\delta<\delta^{* *}$, when following the aggressive investment policy the entrepreneur earns positive expected profits. In contrast, if $\delta>\operatorname{Max}\left[\delta^{*}, \delta^{* *}\right]$, this policy is unprofitable for the entrepreneur. Our results are summarized in the next proposition.

Proposition 15: When $\pi<\frac{2 \beta}{1+\beta}$, if the entrepreneur can commit to the aggressive policy of investing as soon as one of the signals is good, she can obtain positive expected profits if the product market is competitive enough $\left(\delta<\operatorname{Max}\left[\delta^{*}, \delta^{* *}\right]\right)$. In that case there can be overinvestment, in the sense that the entrepreneur can engage with one expert only in projects with large failure rate. In contrast, if $\delta>\operatorname{Max}\left[\delta^{*}, \delta^{* *}\right]$, there is a market breakdown, i.e., there is underinvestment.

\section{Empirical Implications}

Our theoretical analysis highlights the role of the complementarity of expert signals in mitigating the risk of idea stealing. It shows how partnerships should be designed to exploit these features. It also generates predictions on the link between expert complementarity and the distribution of ex post returns, as well as expert compensation. In this section we discuss in turn: i) what variables one could use to proxy for complementarity and what type of dataset could be used to measure these variables, and ii) the implications of our model for the joint distribution of these variables. 
Measurement and data First consider complementarity. Experts with similar backgrounds, e.g., two suppliers of computer systems, are less likely to be strongly complementary than experts coming from different backgrounds, such as, e.g., a computer systems specialist and an expert in marketing of software. But, high-tech ventures will involve experts from similar fields of expertise (e.g. genetists in bio-tech ventures) as long as their knowledge in the area is complementary and necessary for the elaboration of the product. To empirically test our theory, one could use data on the identity of the founding stakeholders of innovative partnerships, which in our model contribute their expertise to the project: What is their line of business, their education, or their prior experience? In which other firms do they hold stakes? What types of products or services (if any) do they supply to the firm? Relying on such information, one could construct a scale to measure complementarity.

In our theoretical framework, ideas with highly complementary signals are not very valuable when only one of the two signals is positive. For such ideas a good fit along the different dimensions is indispensable to create significant value. ${ }^{16}$ This is not unlike the O-ring theory developed by Kremer (1993), positing a production function with many tasks, which must each be successfully completed for the product to have value. This is likely to be the case when success requires different, highly specific, technical or scientific expertises to screen and develop the basic design. Thus, complex high-technology projects are likely to be strongly complementary.

Now consider innovativeness. A "highly novel" idea is one with a very low ex-ante probability of success. In the language of the model, this implies a very low chance of a positive signals on at least some dimension. In other words, an idea is novel if at least one of its aspect is highly unlikely. Ideas with low chance of success on all dimensions must be seen as positively "improbable" concepts. ${ }^{17}$ When successful, they are likely to be "breakthrough ideas." Presumably, more obvious ideas (namely, ideas which are likely to succeed without much screening, given the stock of existing knowledge) are

\footnotetext{
${ }^{16}$ This corresponds to the case when $h$ is low, so that the function $H(n)$ is more convex in the number of positive signals.

${ }^{17}$ Arguably, the chance of success depends on current technological or market knowledge. Novel ideas may then emerge as knowledge becomes sufficiently refined to define them, or to evaluate them.
} 
easier to develop. This ease of evaluation suggests that they resemble other existing products. Hence, they should be less profitable. As a result, "daringness" and idea value in case of success, $H$, should be positively correlated, since a high return is likely only when the concept is very different from existing products.

Testable implications Our analysis implies that, to reduce idea-stealing, experts should be involved as early partners, not as consultants. ${ }^{18}$ Our model also highlights that complementarity reduces the risk of idea stealing, as it provides incentives for specialists to join the partnership, to benefit from the expertise of the others (see Proposition 13). Thus, innovation should be more frequent when it relies on complementary dimensions of expertise. In a cross-section of firms, other things equal, partnerships involving experts with complementary expertise should be more innovative than firms without such expertise in the managing team.

Our model also implies that associating experts to the partnership enhances its chances of success. This is consistent with the evidence discussed by Bhide (2000). Our analysis implies that, other things equal, the likelihood that the project will be successful increases with the number of experts associated with the partnership. Furthermore, the greater the complementarity between the experts, the more positive the effect of the number of experts on the likelihood of success.

Yet, another implication of our theory is that signal complementarity reduces the rents which must be left to the experts. Hence, other things equal, the fraction of the shares of the company allocated to the experts is predicted to decrease in the level of complementarity. Thus, ceteris paribus the stake for the initial entrepreneur (vis a vis, say a pure financier) should be higher in high technology projects with high complexity. Also, experts with more critical expertise should get a higher stake in the partnership than partners with more trivial expertise.

To illustrate the empirical implications of our theory, it is useful to consider two polar cases. The

\footnotetext{
${ }^{18}$ Traditional consultant groups are relatively less active in the Silicon Valley than advisors who often take shares in payment. An example is the marketing "guru" Regis McKenna, who provided his expert advice to many hi-tech ventures.
} 
first one corresponds to "daring" ideas, which are both complex and novel, and thus exhibit high complementarity. Such ideas have a high a priori chance to fail, but, if successful, should be quite profitable, precisely because they represent a radical departure from existing practices. Our model implies that these highly innovative, complex and risky projects require highly specialized experts, joining the firm as early partners.

The opposite polar case corresponds to simple, incremental ideas which are likely to succeed and do not require a precise coincidence of signals. Our theoretical analysis implies that such ideas, with low complexity and complementarity, are very vulnerable to be stolen. They will tend to emerge in older technology sectors, or in consumer oriented products. While their return is safer, it is likely to be low. We would then predict that such ideas would be often implemented with limited screening, and thus with fewer or no expert partners. The original team may include only individuals connected to the innovator by some loyalty links, and thus be likely to be drawn from friend or family circles.

\section{Conclusion}

Following Schumpeter, we have modelled new ideas as novel combinations of existing productive means. Evaluating such new ideas is quite different from valuing an existing asset, whose use is already observable. A new idea has by definition never been implemented, so its features cannot be compared with previous experiences. In the words of Schumpeter (1926): "Outside the usual path, economic agents cannot rely on the data which are available for routine decisions... They can and should forecast and assess ... but in many respects things are quite uncertain."

One crucial question is whether the different aspects of the proposed new combination can be functionally combined. Evaluating this requires experts drawn from the distinct dimensions of the project, whose signals are complementary rather than additive. To screen good ideas, the innovative entrepreneur must first identify the critical ingredients of her business concept. Then, she must aggregate privately observed expert opinions along each complementary dimension of the idea, while 
controlling the incentives experts have to steal the idea. To do so, she offers them to join a partnership. We identify a potential market breakdown, in which a partnership is not viable because stealing the idea is too tempting for the experts. The entrepreneur can successfully avoid such opportunistic actions if each expert is better off joining the partnership to benefit from the advice of the other expert, rather than undertaking the project on his own. This requires that at least one of the expert signals be critical for the success of the project or that the degree of complementarity in the two dimensions of the project be very high. Both conditions relate to the size of the gain in cooperating with other experts.

Our theoretical analysis yields a variety of empirical implications. For example it predicts that innovative projects should associate complementary experts as partners rather than consultants, that associating experts to the partnership enhances its chances of success, and that the stake for the initial entrepreneur should be higher in high-technology enterprises with high complexity and complementarities. It would be interesting to test these implications with data on innovative new firms.

\section{References}

Aghion, P. and J. Tirole, 1994, "On the management of innovation", Quarterly Journal of Economics, $1185-207$.

Aldrich, H.E, "Organizations Evolving", 1999, Sage Publications, London.

Anton, J., and D. Yao, 1994, "Expropriation and Inventions", American Economic Review, 190209.

Anton, J., and D. Yao, 2002, "The sale of ideas: Strategic disclosure, property rights and contracting," Review of Economic Studies, 513-532.

Anton, J. and D. Yao, 2003, "Attracting skeptical buyers", Working paper, Duke University.

Anton, J., and D. Yao, 2004, "Little patents and big secrets: managing intellectual property," Rand Journal of Economics, 1-22. 
Arrow, K., 1962, Economic Welfare and the Allocation of Resources for Inventions, in R. Nelson (ed), The rate and direction of inventive activity: Economic and social factors, Princeton University Press, Princeton.

Baccara, and Razin, 2002, "From thought to practice: Appropriation and endogenous market structure with imperfect intellectual property rights," Working paper, Princeton University.

Besen, S., and L. Raskind, 1991, "An introduction to the law and economics of intellectual property", Journal of Economic Perspectives, 5-1.

Bidhé, Amar V., 2000, "The Origin and Evolution of New Businesses", Oxford University Press

Callon, M., 1989, "La science et ses réseaux", La Découverte, Paris.

Casamatta, C., 2001, "Financing innovation", Working paper, Toulouse University.

Casamatta, C. and C. Haretchabalet, 2002, "Venture capital and syndication", Working Paper, Toulouse University.

Cestone, G., and L. White, 1998, "Anti Competitive Financial Contracting: The Design of Financial Claims", Working Paper, Toulouse University.

Cheung, S., 1992, "Property Rights in Trade Secrets", Economic Inquiry.

DeKoning, A., and Muzyka, 2001, "The convergence of good ideas: How do serial entrepreneurs recognize innovative business ideas," Working Paper, INSEAD.

Dodgson, M., 1993, "Learning, trust and technological collaboration", Human Relations, 46, 77-94.

Fenn, G., N. Liang, and S. Prowse, 1995, "The economics of the private equity market", Board of the Governors of the Federal Reserve System.

Hellmann, Thomas, 2001, "Entrepreneurship and the Process of Obtaining Resource Commitments", mimeo, Stanford University.

Hellmann, Thomas, and Enrico Perotti, 2004, "Circulation of Ideas: Firms versus Markets", mimeo, University of Amsterdam.

Kremer, Michael, 1993. "The O-Ring Theory of Economic Development," The Quarterly Journal of Economics, vol. 108(3), p. 551-75. 
Lazear, E., 2002, "Entrepreneurship", Working paper, Graduate School of Business, Stanford University.

Maskin, E. and J. Tirole, 1990, "The Principal-Agent Relationship with an Informed Principal: I: PrivateValues", Econometrica.

Maskin, E. and J. Tirole, 1992, "The Principal-Agent Relationship with an Informed Principal: II: CommonValues", Econometrica.

Mustar, P., 1998, "Partnerships, configurations and dynamics in the creation and development of SMEs by researchers, Industry and Higher Education", 217-221.

Rajan, R. and L. Zingales, 2001, "The Firm as a Dedicated Hierarchy", Quarterly Journal of Economics.

Schumpeter, J., 1926, "Theorie der wirtschaftlichen Entwicklung, Duncker and Humblot", Berlin. Schumpeter, J., 1942, "Capitalism, Socialism and Democracy", George Allen and Unwin, London. The Economist, "Mercky Prospects", July 13, 2002, pp.51-51

Weitzman, M., 1998, "Recombinant growth", Quarterly Journal of Economics, 331-360.

\section{Appendix: proofs}

Proof of Proposition 2: There are three candidate equilibria where $x$ would contact $y$ and offer her a share $\alpha$ of the project: ${ }^{19}$

First, consider a candidate separating equilibrium where $x$ would offer $y$ a share $\alpha_{G}$ after observing good news and a share $\alpha_{B}$ after bad news: In that case, when she is offered $\alpha_{G}, y$ realizes that $x$ has observed a good signal. Would she be interested in collaborating with $x$ when she has observed a good signal ? No. After observing a good signal, $y$ would be better off reporting a bad signal to walk away

\footnotetext{
${ }^{19}$ For simplicity we consider only the case where the first expert offers the other expert a share of the project, i.e., an equity stake. In our simple model, allowing for more general contracts would not alter the result. Also for simplicity we focus on pure strategies equilibria.
} 
from $x$, implement the project by herself, and earn the entire value of the project: $\mu H+(1-\mu) h-2 c$. Anticipating this reaction, $x$ does not find it attractive to share the idea with $y$ after observing a good signal.

Now consider the case where $x$ would offer $\alpha_{B}$ to $y$. After observing a bad signal, $y$ would reject this offer because she would know the project cannot yield any cash flow. After observing a good signal, she could accept $x$ 's offer only if: $\alpha_{B} h-c>0$, that is: $\alpha_{B}>\frac{c}{h}$. On the other hand, $x$ 's rationality condition requires that:

$$
\left(1-\alpha_{B}\right) h-c>0 \Leftrightarrow 1-\alpha_{B}>\frac{c}{h} \Leftrightarrow 1-\frac{c}{h}>\alpha_{B}
$$

Together, the two conditions imply that: $h>2 c$, which contradicts our assumptions. Hence, there is no separating equilibrium where $x$ could collaborate with $y$ by offering her a share $\alpha_{G}$ after observing good news and a share $\alpha_{B}$ after bad news.

Second, consider a candidate equilibrium where the expert would steal the idea and contact another expert only after observing a good signal. ${ }^{20}$ In that case, the second expert infers the signal of the first expert from the mere fact that she is contacted. Following the same logic as in the first candidate equilibrium, in this context the first expert cannot avoid idea stealing.

Third consider a candidate pooling equilibrium where $x$ would contact $y$ and offer her a share irrespective of his own signal. Could expert $y$ accept this offer after observing a negative signal? In that case, her individual rationality condition would imply: $\alpha \pi_{x} h>c \Leftrightarrow \alpha>\frac{c}{\pi_{x} h}$. On the other hand, the individual rationality condition of expert $\mathrm{x}$ after observing a bad signal would imply: $(1-\alpha) \pi_{y} h>$ $c \Leftrightarrow 1-\alpha>\frac{c}{\pi_{y} h} \Leftrightarrow 1-\frac{c}{\pi_{y} h}>\alpha$. The two conditions together imply: $1-\frac{c}{\pi_{x} h}>\frac{c}{\pi_{y} h} \Leftrightarrow 1>\frac{c}{\pi_{y} h}+\frac{c}{\pi_{x} h}$.In turn this implies: $1>\frac{2 c}{h}$, which contradicts our assumptions. Hence, there is no pooling equilibrium where $y$ accepts the offer when she has observed a bad signal.

Could there be an equilibrium where she would accept the offer only after observing a good signal? This would require that she prefers to accept the offer than to undertake the project alone, i.e.:

\footnotetext{
${ }^{20}$ Stealing the idea to undertake it only after observing a bad signal is obviously not a profitable strategy.
} 
$\alpha\left[\pi_{x}(\mu H+(1-\mu) h)+\left(1-\pi_{x}\right) h\right]-c>\pi_{x}(\mu H+(1-\mu) h)+\left(1-\pi_{x}\right) h-2 c$. This is equivalent to:

$$
\frac{c}{\left[\pi_{x}(\mu H+(1-\mu) h)+\left(1-\pi_{x}\right) h\right]}>1-\alpha .
$$

On the other hand, the individual rationality of expert $x$, if he has observed a bad signal, is: $\pi_{y}[(1-$ $\alpha) h-c]>0$, i.e., $1-\alpha>\frac{c}{h}$. The two conditions imply that: $\frac{c}{\pi_{x}(\mu H+(1-\mu) h)+\left(1-\pi_{x}\right) h}>\frac{c}{h}$, that is: $\pi_{y} h>\pi_{x}(\mu H+(1-\mu) h)+\left(1-\pi_{x}\right) h \Leftrightarrow h>H$, a contradiction.

\section{QED}

Proof of Proposition 9: Since none of the experts can undertake the project alone, their incentive compatibility condition in the good state does not bind. Hence, the program of the entrepreneur is to maximize:

$$
\pi_{y} \pi_{x}\left[\mu\left(H-\varphi_{x}(H)-\varphi_{y}(H)\right)+(1-\mu)\left(h-\varphi_{x}(h)-\varphi_{y}(h)\right)\right]
$$

under the incentive compatibility condition of the experts in the bad state: $\varphi_{k}(h)<c, k \in\{i, j\}$, and the rationality conditions of the experts: $\mu \varphi_{i}(H)+(1-\mu) \varphi_{i}(h) \geq c \quad$ for $i \in\{x, y\}$.Saturating the rationality condition, and substituting it in the objective of the entrepreneur, the latter becomes: $\pi_{y} \pi_{x}[\mu H+(1-\mu) h-2 c]$, i.e., the command variables cancel out, and the entrepreneur earns positive profits. Hence, any transfer function satisfying the rationality conditions is an optimum. For example, set: $\varphi_{k}(h)=h / 2, k \in\{i, j\}$. Thus, the incentive compatibility condition in the bad state holds, and the rationality condition becomes: $\mu \varphi_{i}(H)+(1-\mu) \frac{h}{2}=c \quad$ for $i \in\{x, y\}$, that is: ${ }^{21} \varphi_{i}(H)=\frac{c-\frac{1-\mu}{2} h}{\mu}$ for $i \in\{x, y\}$.

\section{QED}

Proof of Proposition 10: Since only expert $y$ is critical, her incentive compatibility condition in the good state binds, while for expert $\mathrm{x}$, we only need to impose the rationality condition. Hence,

\footnotetext{
${ }^{21}$ Note that this is consistent with limited liability since, with $\varphi_{k}(h)=h / 2, k \in\{i, j\}$, the expected profit of the entrepreneur is: $\pi_{y} \pi_{x}\left[\mu\left(H-\varphi_{x}(H)-\varphi_{y}(H)\right)\right]$. That this profit is positive implies that: $H>\varphi_{x}(H)-\varphi_{y}(H)$.
} 
the program of the entrepreneur is to maximize:

$$
\pi_{y} \pi_{x}\left[\mu\left(H-\varphi_{x}(H)-\varphi_{y}(H)\right)+(1-\mu)\left(h-\varphi_{x}(h)-\varphi_{y}(h)\right)\right]
$$

under the incentive compatibility condition of the experts in the bad state: $\varphi_{k}(h)<c, k \in\{i, j\}$, the rationality condition of the expert $x: \mu \varphi_{x}(H)+(1-\mu) \varphi_{x}(h) \geq c$, and $y^{\prime}$ s incentive compatibility condition in the good state:

$$
\pi_{x}\left[\mu \varphi_{y}(H)+(1-\mu) \varphi_{y}(h)-c\right] \geq \pi_{x}[\mu H+(1-\mu) h]+\left(1-\pi_{x}\right) h-2 c .
$$

Let these incentive rationality conditions hold as equalities and substitute them in the objective of the entrepreneur, the latter simplifies to: $\pi_{y}\left(1-\pi_{x}\right)(2 c-h)$.Here also the command variables cancel out, and the entrepreneur earns positive profits. Hence, any transfer function satisfying the rationality condition of $x$, and the incentive compatibility condition of $y$ is an optimum. For example, set: $\varphi_{k}(h)=h / 2, k \in\{i, j\}$. Thus, the incentive compatibility condition in the bad state holds, and the rationality condition of $x$ becomes: $\varphi_{x}(H)=\frac{c-\frac{1-\mu}{2} h}{\mu}$. The incentive compatibility condition of $y$ in the good state becomes: $\varphi_{y}(H)=H+\frac{1-\mu}{\mu} h / 2+\frac{1-\pi_{x}}{\mu \pi_{x}} h-\frac{c}{\mu}\left(\frac{2}{\pi_{x}}-1\right)$, which pins down the value of the transfer to $y$ in that state. ${ }^{22}$

\section{QED}

Proof of Proposition 11: Since none of the experts is critical, their incentive compatibility conditions in the good state bind. Hence, the program of the entrepreneur is to maximize:

$$
\pi_{y} \pi_{x}\left[\mu\left(H-\varphi_{x}(H)-\varphi_{y}(H)\right)+(1-\mu)\left(h-\varphi_{x}(h)-\varphi_{y}(h)\right)\right]
$$

under the incentive compatibility condition of the experts in the bad state: $\varphi_{k}(h)<c, k \in\{i, j\}$, and their incentive compatibility condition in the good state:

$$
\pi_{i}\left[\mu \varphi_{j}(H)+(1-\mu) \varphi_{j}(h)-c\right] \geq \pi_{i}[\mu H+(1-\mu) h]+\left(1-\pi_{i}\right) h-2 c,(i, j) \in\{(x, y),(y, x)\} .
$$

\footnotetext{
${ }^{22}$ Again, note that these transfers are consistent with limited liability.
} 
Let the latter hold as equalities:

$$
\begin{aligned}
& \mu \varphi_{y}(H)+(1-\mu) \varphi_{y}(h)=[\mu H+(1-\mu) h]+\frac{1-\pi_{x}}{\pi_{x}} h-c\left(\frac{2}{\pi_{x}}-1\right), \\
& \mu \varphi_{x}(H)+(1-\mu) \varphi_{x}(h)=[\mu H+(1-\mu) h]+\frac{1-\pi_{y}}{\pi_{y}} h-c\left(\frac{2}{\pi_{y}}-1\right),
\end{aligned}
$$

Substituting these equalities in the objective of the entrepreneur, the latter becomes:

$$
\pi_{y} \pi_{x}\left[-[\mu H+(1-\mu) h]-\frac{1-\pi_{x}}{\pi_{x}} h+c\left(\frac{2}{\pi_{x}}-1\right)-\frac{1-\pi_{y}}{\pi_{y}} h+c\left(\frac{2}{\pi_{y}}-1\right)\right],
$$

This is negative if:

$$
\mu H+(1-\mu) h+\frac{1-\pi_{x}}{\pi_{x}} h+\frac{1-\pi_{y}}{\pi_{y}} h>2 c\left(\frac{1}{\pi_{x}}+\frac{1}{\pi_{y}}-1\right),
$$

which is equivalent to the condition stated in the proposition.

It only remains to propose a transfer function. Set: $\varphi_{k}(h)=h / 2, k \in\{i, j\}$. The incentive compatibility condition becomes:

$$
\begin{aligned}
& \varphi_{y}(H)=\left[H+\frac{1-\mu}{\mu} \frac{h}{2}\right]+\frac{1-\pi_{x}}{\pi_{x}} \frac{h}{\mu}-\frac{c}{\mu}\left(\frac{2}{\pi_{x}}-1\right), \\
& \varphi_{x}(H)=\left[H+\frac{1-\mu}{\mu} \frac{h}{2}\right]+\frac{1-\pi_{y}}{\pi_{y}} \frac{h}{\mu}-\frac{c}{\mu}\left(\frac{2}{\pi_{y}}-1\right),
\end{aligned}
$$

which pins down the value of the transfers. ${ }^{23}$

\section{QED}

Proof of Proposition 14: First consider the case of equity financing: The entrepreneur offers each of the experts a fraction $\alpha$ of the revenues of the project. First consider the case where the experts are critical $(\pi<\beta)$. Their participation constraint binds. Hence: $\alpha=\frac{c}{\mu H+(1-\mu) h}$. Our positive NPV assumption implies that $\alpha<1 / 2$. It only remains to check that this is consistent with the no gambling condition: $\alpha h<c$.Substituting the value of $\alpha$ obtained from the break even constraint, the

\footnotetext{
${ }^{23}$ Again, note that this is consistent with limited liability.
} 
no gambling condition holds iff: $\frac{c h}{\mu H+(1-\mu) h}<c$. This amounts to $h<\mu H+(1-\mu) h$ which obviously holds.

Second consider the case where the experts are not critical $(\pi>\beta)$. Their no stealing condition is:

$$
\pi[\alpha(\mu H+(1-\mu) h)-c] \geq \pi[\mu H+(1-\mu) h]+(1-\pi) h-2 c .
$$

That is:

$$
\alpha \geq 1-\frac{\frac{2-\pi}{\pi} c-\frac{1-\pi}{\pi} h}{(\mu H+(1-\mu) h)}
$$

By construction, when there is no market breakdown, the right hand side is lower than one half. Thus the no stealing condition is is consistent with the no gambling condition iff:

$$
\frac{c}{h} \geq 1-\frac{\frac{2-\pi}{\pi} c-\frac{1-\pi}{\pi} h}{(\mu H+(1-\mu) h)}
$$

which holds since the right-hand side is lower than 1 and $c>h$.

Now, turn to the case of convertible bonds. The details of the face value of the bond, the conversion rate and the exercise strategies are as follows: As shown in the proofs above, the transfer to the experts when the cash flow is low can be set to: $\varphi_{k}(h)=h / 2, k \in\{i, j\}$.The transfer to the experts when the cash flow is high is: $\varphi_{k}(H), k \in\{i, j\}$. Set the conversion rate of the bond to: $\gamma_{k}=\varphi_{k}(H) / H$. Each of the two experts rationally expects the other expert to convert his (or her) bond in the high cash flow state. Thus, each expert expects to obtain: $\gamma_{k} H=\varphi_{k}(H)$ if he (or she) converts. Since, as stated in the previous proposition, the transfer function is increasing in the cash flow from the project, the payoff obtained in state $H$ by each expert if he (or she) converts: $\gamma_{k} H=\varphi_{k}(H)$, is greater than what he (or she) obtains when not converting: $\varphi_{k}(h)=\frac{h}{2}$. Thus, both experts indeed prefer to convert in state $H$.

\section{QED}




\section{Figure 1: The expected cash flow function}






\section{Figure 2: Criticality \& feasibility of the partnership}

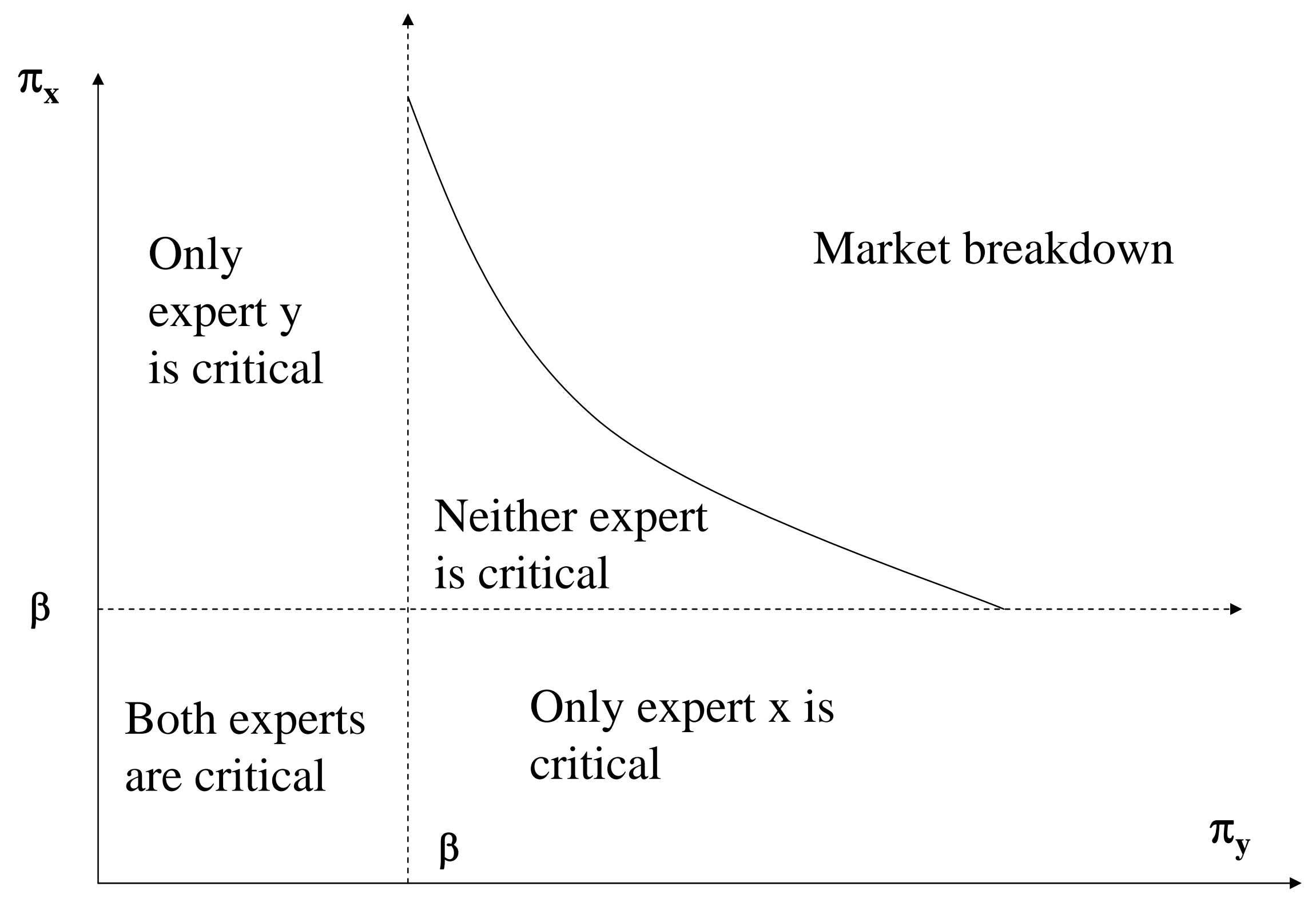




\section{Figure 3: The expected profit of the entrepreneur}

Expected profit of the entrepreneur

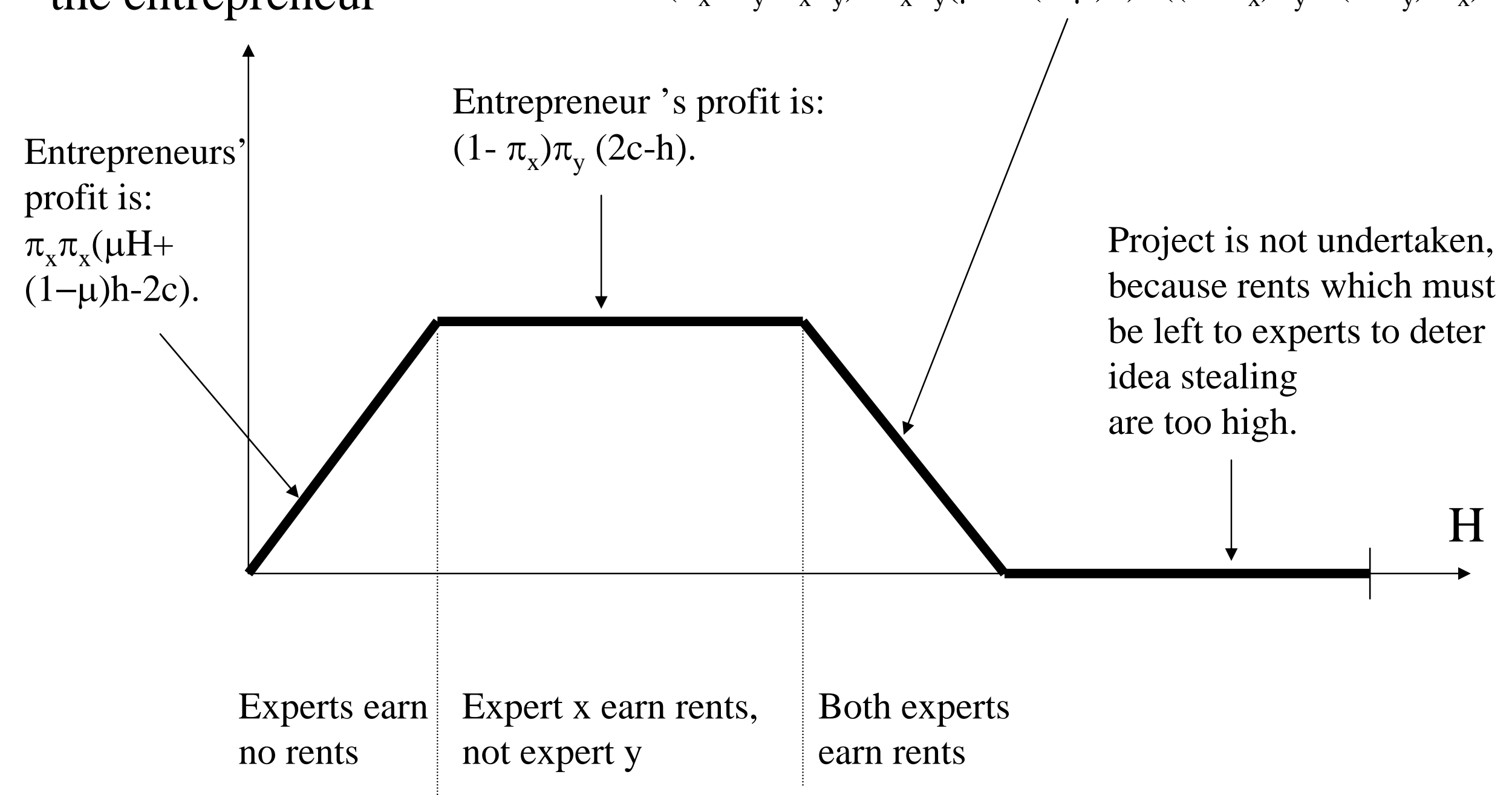

Entrepreneur 's profit is:

$2 \mathrm{c}\left(\pi_{\mathrm{x}}+\pi_{\mathrm{y}}-\pi_{\mathrm{x}} \pi_{\mathrm{y}}\right)-\pi_{\mathrm{x}} \pi_{\mathrm{y}}(\mu \mathrm{H}+(1-\mu) \mathrm{h})-\left(\left(1-\pi_{\mathrm{x}}\right) \pi_{\mathrm{y}}+\left(1-\pi_{\mathrm{y}}\right) \pi_{\mathrm{x}}\right) \mathrm{h}$. 